\title{
Microeconomics of intertemporal choice in zero-space during Covid-19: a behavioral economics perspective
}

\author{
Javier Cifuentes-Faura ${ }^{1} \cdot$ Renaud Di Francesco ${ }^{2}$ \\ Accepted: 20 October 2021 / Published online: 9 November 2021 \\ ๑) The Author(s), under exclusive licence to Springer-Verlag GmbH Germany, part of Springer Nature 2021
}

JEL Classification D01 · D1 · D9

\section{Editorial}

Behavioral Economics has been seen to gain importance through its active contribution to reducing, mitigating and hopefully stopping 1 day the propagation of the Covid-19 pandemic. Vaccination and other prevention programs, many qualifying as Non-Pharmaceutical Interventions are supported by the methodology established in Behavioral Economics, to nudge and reinforce actions with positive impact, and deter actions with negative impact. All biases can significantly influence human behavior in a person's dayto-day life, so it is important to study the meaning of zerospace in a lockdown phase of the Covid-19 pandemic and the activities of household members as agents and beneficiaries. This editorial reviews different aspects of the impact of the pandemic on the economy, and the operational coming into play of behavioral economics tools. It has been shown the nanoeconomics of households under lockdown, modeled using agent models and behavioral economics, where time and activities allocations in time were critical to the continuation of life in the circumstances.

Javier Cifuentes-Faura javier.cifuentes@um.es

Renaud Di Francesco

Rdifrancesco@ymail.com

1 University of Murcia, Murcia, Spain

2 The Institution of Engineering and Technology, London, UK

\section{From global to local aspects, and bottom-up behavioral incentives}

The Covid-19 emerged in China in late 2019, causing millions of infections and deaths worldwide [1-3]. An international health emergency and pandemic was generated [4] with unprecedented impact on health systems, societies, and the economy [5, 6]. In the face of this crisis, many governments have imposed restrictive measures to contain the spread of the pandemic, such as home confinement [7], school closures [8] along with the obligation to move to online teaching [9], mobility restrictions [10] or even the temporary closure of non-essential activities [11].

This pandemic has led to a change of individual attitude in many citizens [12]. Whereas the propagation of Covid19 has been duly documented by national and international health authorities relying on classical comprehensive national models, new investigations going in the other direction, benefiting from a behavioral framing have elucidated propagation scenarios in specific contexts of interest such as elderly care homes which experienced dramatic death rates [13], large events, polling stations for voting, an individual household in lockdown [14].

During the pandemic caused by Covid-19, Behavioral Economics methods have come to the forefront [15], with public decision makers in charge of defining and implementing Non-Pharmaceutical Interventions [16] framing [17] the options presented to people, in such a manner that people adhere to measures, and are nudged [18] into "good hygiene behaviours" improving the overall outcome for society. People have had to get used to a new order, which includes continuous cohabitation with family members, control of family time and space, adaptation of learning and work space, lack of space for sport, etc. All these can lead to lack of self-care, fear, weight gain, changes in physical activity and eating habits, stress, irritability, etc. 


\section{Importance of behavioral economics during the pandemic}

Behavioral economics studies how psychological, social or cognitive factors affect the economic decisions of individuals. It seeks to modify behavior in a positive way and minimize 'biases' in people's decision making, and explains a wide variety of human activities and behavior.

It derives from reflections on rational choice theory by developing a systemic way of analyzing elements such as willpower, self-interest and rationality in decision making [19]. Thus, with the use of economic reflections and analysis from psychological assumptions, it can be observed that human decisions are not free from judgment bias [20].

Real-life observations show that human beings are not always guided in their behaviors by a narrow view of their own self-interest, as economists, over the centuries since Adam Smith, would have preferred them to be. Economic agents are sometimes willing to sacrifice their own self-interest to satisfy different forms of social preferences [21]. The methodology used by behavioral economics consists of locating the anomalies of traditional economic models and resorting to elements mainly from psychology, with the aim of providing an analytical framework and greater precision to investigate the behavior of individuals in decision processes [22].

Behavioral economics is being applied to a large extent in the area of health, to try to improve people's habits [23]. Hence, also the importance of applying it in an era marked by Covid-19. It seeks that, through small nudges, or the socalled "Nudge" [18], individuals choose with help, but without restricting or limiting options. The aim is for citizens to have the capacity to decide on what is appropriate for their lives in a rational way.

Thaler and Sustein [18] define nudge as "Any aspect of the choice architecture that alters people's behavior in a predictable way without prohibiting any choice or significantly changing their economic incentives" (p.6). Thus, the definition of the term poses a contrast with interventions based on economic incentives. Three important concepts are brought to light by behavioral economics as key motivators of agents: loss aversion, overconfidence, and self-control.

The crisis caused by the coronavirus has made Behavioral Economics acquire a very important role for planning actions to stop the pandemic $[24,25]$. Behaviors that are not appropriate to combat efficiently the pandemic had to be identified in their context of appearance, with detail study of propagation scenarios in specific interaction cases [14], as well as human biases intervening in the perceptions towards public measures. With simple tools and messages, appropriate changes in human behavior were encouraged or "nudged" (using Thaler's word). There are many biases related to human behavior. They were aggravated as a consequence of the pandemic, as shown in the following section.

\section{Behavioral biases during the Covid-19 pandemic}

The Covid-19 epidemic has created an environment of uncertainty and lack of control among the population. Misinformation has further fostered the emergence of behavioral biases [26-28].

The existence of cognitive biases [29, 30] arises as a need for immediate judgment. The brain assumes a quick position in the face of certain stimuli, which due to the inability to process all available information is filtered selectively or subjectively. Among others, we can fundamentally distinguish the following biases, aggravated by the emergence of the Covid-19 pandemic: hindsight [31], confirmation [32], optimism [33], present [34], loss aversion [35], bandwagon [36], control illusion [37], recent experience [38], and conservation [39].

All biases above can significantly influence human behavior during Covid-19 [40]. To perform certain behaviors or actions, agents need a motivation, an ability and a stimulus [41]. If a certain action is intended to be done, it must be easy and quick for people to be motivated. Therefore, even activities as common during a pandemic as hand washing or putting on a mask require that the person be motivated to perform these behaviors. These biases will also influence the individual's purchasing process or household savings decisions, as well as in the day-to-day life of the individual.

\section{The meaning of zero-space in a lockdown phase}

Seen from outside of the home, the household members live in the same "cellular location". Naturally, seen from the inside of the home, there are further divisions in the "cellular space": rooms, with their space and functionalities, and there are corridors and stairs, doors and windows. It is important for household members to have the ability to have privacy when needed, for instance to perform work tasks such as calls, or to isolate for health reasons and preventing the transmission of Covid-19 from a potentially infectious household member to a seemingly healthy household member. Let us describe below a realistic model for a household under lockdown and analyze how optimization and trade-offs might be needed for mutual satisfaction of all household members and economic system sustainability. The agents are household members (children 
of school age, and adults). The daytime activities of adult household members are working from home (in the case modeled) or leisure, whenever they must not supervise children or prepare or attend a meal. The daytime activities of children are education sessions or leisure sessions or attending a meal.

\section{Activities of household members and agents and beneficiaries: agent-based model in practice}

We note that activities compete for attention: agents can be considered resources, and activities as requesters.

The time and resource allocation in "zero-space" (lockdown) happening during the 2019-2021 pandemic, new for the twenty-first century, can compare with a well-known and understood, millennium old, monastic life model, still valid today for the Solesmes Abbey in France for instance, ${ }^{1}$ with a very regular time plan.

There is naturally an issue of fair scheduling and fair allocation. The ideal world would spread enjoyable and less enjoyable tasks and leisure times evenly on the adult members of a household. The observed reality is unfortunately different, with centuries of inequalities still casting a shadow on households in lockdown.

A report issued by the UK Institute for Fiscal Studies (IFS) informs on "How are mothers and fathers balancing work and family under lockdown?" [42]. Let us quote just one sentence of this report and refer to the public report for in-depth facts and analysis. The data collected show that "Compared with fathers, mothers are spending less time on paid work but more time on household responsibilities. The time they spend on paid work is also more likely to be interrupted with household responsibilities."

The description given above of households under lockdown would rather encourage to use game theoretical models, where agents and beneficiaries (collectively called the stakeholders) play cooperatively for mutual benefit, and trade activities allocated, as allowed and possible, for stepwise of comprehensive improvement of their satisfaction.

When you are locked down with someone else, possibly several other people, keeping everyone happy, and reducing the occasional risk of moments of unhappiness or discontent is of paramount importance. Being locked down with a partner is a strength test for the relationship.

One could use the analogy with a LASER signal, which forms as waves bounce back and forth within a cavity named klystron, with the interesting effect giving its name

\footnotetext{
${ }^{1}$ For more information: Abbaye Saint Pierre, Solesmes "A Day in the Life of a Monk" https://www.solesmes.com/day-life-monk.
}

to LASER: light amplification through simulated emitted radiations.

The schedule view of a household in lockdown, as in the illustration above, could hint to balance with robust condition and healthy cooperative mindset, respecting each of the partners, or towards an imbalance, repeated over time, which wears on people, and negatively impacts their relationship.

A special point for lockdown is that weekdays seem very similar to one another, and so do the weekend days. No move in space is possible as in previous normal life, before the pandemic and the lockdown, no change of horizon. Our lives are boxed in a limited space. Events and life itself become very determined, and they are replicated with a daily periodicity and a possible change between weekdays and weekend, which may not even be felt as positive: weekends are time on your hands, and no freedom to move in space (again the "zero-space" characterization we have given for lockdown).

Daily periodicity with two regimes: week (work)-days and weekend, and above a weekly periodicity. Next week is like the last week.

\section{Applying behavioral economics to reduce health and household economic spillovers}

Since social distancing can lead to a loss of mental and physical well-being in individuals, also decreasing productivity, governments need to convey messages to the population about good practices for staying healthy and managing anxiety. Simple motivational messages should be displayed and adhered to (or modified to get adherence).

Constrained cohabitation among household members has put pressure on each, requiring, good practices to be implemented and respected by all.

During confinement, some people have experienced anxiety or boredom sometimes compensated with excessive drinking or eating. Nudging them back to healthier behaviors should be considered by Public Policy Makers.

Before the pandemic, very few people were teleworking, so they have had to adapt to working from home and balancing work, family responsibilities and leisure. Faced with this great challenge, it has been necessary to define a strict work schedule, create a calendar of activities at family level. For their part, students had to be more autonomous as well as disciplined, hence the need for adaptation and nudging as appropriate.

Behavioral economics interventions discussed above tend to modify behavior without restricting people's ability to choose. 


\section{Conclusions}

During the pandemic caused by Covid-19, Behavioral Economics methods have come to the forefront-it is necessary to identify those human biases and modify those behaviors that are not appropriate to combat the pandemic.

All biases can significantly influence human behavior in a person's day-to-day life, so it is important to study the meaning of zero-space in a lockdown phase and the activities of household members and agents and beneficiaries.

This paper has reviewed different aspects of the impact of the pandemic on the economy, and with the tools of behavioral economics coming into play, it can help to:

(i) The nanoeconomics of households under lockdown, modeled using agent models and behavioral economics, where time and activities allocations in time were critical to the continuation of life in the circumstances.

(ii) The nudging of health-protecting behaviors in the population by policy makers, using behavioral economics methods in their implementation of NonPharmaceutical Intervention (NPI) measures.

(iii) The rationale and context for economic support packages by governments and their perception and acceptance by the population.

\section{References}

1. Tanne, J.H., Hayasaki, E., Zastrow, M., Pulla, P., Smith, P., Rada, A.G.: Covid-19: how doctors and healthcare systems are tackling coronavirus worldwide. BMJ 368, m1090 (2020). https://doi.org/ 10.1136/bmj.m1090

2. Velavan, T.P., Meyer, C.G.: The COVID-19 epidemic. Trop. Med. Int. Health 25(3), 278 (2020)

3. Adams, J.G., Walls, R.M.: Supporting the health care workforce during the COVID-19 global epidemic. JAMA 323(15), 14391440 (2020)

4. Sohrabi, C., Alsafi, Z., O'Neill, N., Khan, M., Kerwan, A., AlJabir, A., Agha, R.: World Health Organization declares global emergency: a review of the 2019 novel coronavirus (COVID-19). Int. J. Surg. 76, 71-76 (2020)

5. Nicola, M., Alsafi, Z., Sohrabi, C., Kerwan, A., Al-Jabir, A., Iosifidis, C., Agha, R.: The socio-economic implications of the coronavirus and COVID-19 pandemic: a review. Int. J. Surg. 78, 185-193 (2020)

6. Cifuentes-Faura, J.: Crisis del coronavirus: impacto y medidas económicas en Europa y en el mundo. Espaço Econ. Rev. Bras. Geogr econ. (18) (2020). https://doi.org/10.4000/espacoeconomia. 12874

7. Ammar, A., Chtourou, H., Boukhris, O., Trabelsi, K., Masmoudi, L., Brach, M., ECLB-COVID19 Consortium: COVID-19 home confinement negatively impacts social participation and life satisfaction: a worldwide multicenter study. Int. J. Environ. Res. Public Health 17(17), 6237 (2020)

8. Viner, R.M., Russell, S.J., Croker, H., Packer, J., Ward, J., Stansfield, C., Booy, R.: School closure and management practices during coronavirus outbreaks including COVID-19: a rapid systematic review. Lancet Child Adolesc. Health 4(5), 397-404 (2020)

9. Cifuentes-Faura, J.: Consecuencias en los niños del cierre de escuelas por Covid-19: el papel del gobierno, profesores y padres. Rev. Int. Educ. Justicia Soc. 9(3), 1-12 (2020)

10. Cifuentes-Faura, J.: Analysis of containment measures and economic policies arising from COVID-19 in the European Union. Int. Rev. Appl. Econ. 35(2), 242-255 (2021)

11. Ziedan, E., Simon, K. I., \& Wing, C.: Effects of state COVID19 closure policy on non-COVID-19 health care utilization (No. w27621). Natl Bureau Econ Res. (2020)

12. Di Francesco, R.: Microeconomics of inter-temporal choice in zero- space: -learning from Covid 19 households in lockdown. ResearchGate (2020). https://doi.org/10.13140/RG.2.2.22210. 61129

13. Di Francesco, R.: Covid19 impact on the Elderly Case of Francea quick note. ResearchGate (2020). https://doi.org/10.13140/RG.2. 2.12406.01606

14. Di Francesco, R.: Agent based model for Covid 19 transmission: -field approach based on context of interaction. ResearchGate (2020). https://doi.org/10.13140/RG.2.2.24583.83364

15. Soofi, M., Najafi, F., Karami-Matin, B.: Using insights from behavioral economics to mitigate the spread of COVID-19. Appl. Health Econ. Health Policy 18(3), 345-350 (2020)

16. Morse, S.S.: Pandemic lessons. Disaster Med. Public Health Prep. 14(4), 427-428 (2020)

17. Kahneman, D., Tversky, A.: Choices, values, and frames. In: Handbook of the fundamentals of financial decision making: Part I, pp. 269-278. World Scientific Publishing, Singapore (2013)

18. Thaler, R.H., Sunstein, C.R.: Nudge. Improving decisions about health, wealth, and happiness. Yale University Press, New Haven (2008)

19. Heshmat, S.: Eating behavior and obesity: behavioral economics strategies for health professionals. Springer Publishing Company, New York (2011)

20. Kahneman, D.: Foreword. In: Shafir, E. (ed.) The behavioral foundations of public policy, pp. vii-ix. Princeton University Press, New Jersey (2013)

21. Fatás, E.Y., Roig, J.M.: Una introducción a la metodología experimental en economía. Cuadernos de Economía, Número 27, 7-36 (2004)

22. Muñoz-Munguía, A.M., Borbón-Morales, C.G., Laborín-Álvarez, J.F.: Economía del Comportamiento: un campo fértil para la investigación de aplicaciones en política pública para México. Estudios sociales. Revista de alimentación contemporánea y desarrollo regional, 29(53), (2019)

23. Samson, A.: The behavioral economics guide 2017 (with an introduction by Cass Sunstein). Behav. Econ. Group (2017)

24. Cifuentes-Faura, J.: The importance of behavioral economics during COVID-19. J. Econ. Behav. Stud. 12(3), 70-74 (2020)

25. Haushofer, J., Metcalf, J.C.E.: Combining behavioral economics and infectious disease epidemiology to mitigate the COVID-19 outbreak, pp. 1-10. Princeton University, Princeton (2020)

26. Mian, A., Khan, S.: Coronavirus: the spread of misinformation. BMC Med. 18(1), 1-2 (2020)

27. Cifuentes-Faura, J.: Infodemics during COVID-19: resources and recommendations to combat it. Online Inf. Rev. (2020)

28. Roozenbeek, J., Schneider, C.R., Dryhurst, S., Kerr, J., Freeman, A.L., Recchia, G., Van Der Linden, S.: Susceptibility to misinformation about COVID-19 around the world. Royal Soc. Open Sci. 7(10), 201199 (2020)

29. Gigerenzer, G.: How to make cognitive illusions disappear: BEYOND "heuristics and biases." Eur. Rev. Soc. Psychol. 2(1), 83-115 (1991) 
30. Haselton, M.G., Nettle, D., Murray, D.R.: The evolution of cognitive bias. In: The handbook of evolutionary psychology, pp. 1-20. John \& Wiley Sons Inc, New York (2015)

31. Christensen-Szalanski, J.J., Willham, C.F.: The hindsight bias: a meta-analysis. Organ. Behav. Hum. Decis. Process. 48(1), 147168 (1991)

32. Oswald, M.E., Grosjean, S.: Confirmation bias. In: Cognitive illusions: A handbook on fallacies and biases in thinking, judgement and memory, p. 79. Psychology Press, Hove (2004)

33. Sharot, T., Riccardi, A.M., Raio, C.M., Phelps, E.A.: Neural mechanisms mediating optimism bias. Nature 450(7166), 102105 (2007)

34. O'Donoghue, T., Rabin, M.: Present bias: Lessons learned and to be learned. Am. Econ. Rev. 105(5), 273-279 (2015)

35. Tversky, A., Kahneman, D.: The framing of decisions and the psychology of choice. Science 211(4481), 453-458 (1981)

36. Kahneman, D., Knetsch, J.L., Thaler, R.H.: Anomalies: the endowment effect, loss aversion, and status quo bias. J. Econ. Perspect. 5(1), 193-206 (1991)

37. Budescu, D.V., Bruderman, M.: The relationship between the illusion of control and the desirability bias. J. Behav. Decis. Mak. 8(2), 109-125 (1995)
38. Phillips-Wren, G., Power, D.J., Mora, M.: Cognitive bias, decision styles, and risk attitudes in decision making and DSS. J Decis. Syst. 28(2), 63-66 (2019)

39. Luo, G.Y.: Conservatism bias in the presence of strategic interaction. Quantitative Finance 13(7), 989-996 (2013)

40. Landucci, F., Lamperti, M.: A pandemic of cognitive bias. Intensive Care Med. 47(5), 636-637 (2021)

41. Fogg, B.: A behavior model for persuasive design. In: Proceedings of the 4th international Conference on Persuasive Technology, pp. 40. ACM (2009)

42. Sevilla, A., Phimister, A., Krutikova, S., Kraftman, L., Farquharson, C., Costa Dias, M., Andrew, A.: How are mothers and fathers balancing work and family under lockdown. Institute for Fiscal Studies, London (2020). https://doi.org/10.1920/BN.IFS

Publisher's Note Springer Nature remains neutral with regard to jurisdictional claims in published maps and institutional affiliations. 